International Journal of Advanced Trends in Computer Science and Engineering Available Online at http://www.warse.org/IJATCSE/static/pdf/file/ijatcse8891.42020.pdf

https://doi.org/10.30534/ijatcse/2020/8891.42020

\title{
Upper Extremity Muscle Force for Traditional Archery using Khatrah Technique
}

\author{
Muhammad Shahimi Ariffin ${ }^{1}$, Rohilah Sahak ${ }^{2}$, Azmin Sham Rambely ${ }^{3}$, Muhammad Athif Mat Zin ${ }^{4}$ \\ ${ }^{1}$ Faculty of Science and Technology, Universiti Kebangsaan Malaysia, Malaysia, msa.mushariff@ gmail.com \\ ${ }^{2}$ AME Training Academy, Petaling Jaya, Malaysia, rohilahsahak@yahoo.com \\ ${ }^{3}$ Faculty of Science and Technology, Universiti Kebangsaan Malaysia, Malaysia, asr@ukm.edu.my \\ ${ }^{4}$ Faculty of Science and Technology, Universiti Kebangsaan Malaysia, Malaysia, athief91@yahoo.com
}

\begin{abstract}
This study investigated the behaviour of archer's muscle in six phases of archery cycle known as stance (S), knocking arrow (NA), pre-drew (PD), full draw (FD), release (R) and follow through (FT). Firstly, muscle data at bow arm and draw arm are collected from a world class archer that performed archery with the $45 \mathrm{lb}$ traditional composite bow with Khatrah technique. The data are collected by using Electromyography (EMG) sensor. The sensor is placed on ten significant muscles. In order to standardise the time frame of data and suppress noise, the extracted data is normalised and smoothed respectively. Further, muscle forces are gauged and compared in each phase. Result obtained shows that high muscle force at upper and lower arm acquired at bow arm, while trunk body part for draw arm. Furthermore, using Khatrah technique, the most affected muscle is flexor carpi radialis at the bow arm. This study provides the foundation for the development of system to monitor the muscle condition of archers.
\end{abstract}

Key words: Muscles activity, Electromyography (EMG), Traditional archery, Khatrah technique, Muscle fatigue.

\section{INTRODUCTION}

Archery is a static sport that requires the strength and endurance of the upper extremity by propelling the arrow to the target while shooting [1,2]. Archery is mainly performed by two arms called a draw arm and a bow arm. The bow arm is arm of the hand that holds the bow, while the draw arm is the arm of shooting hand. Compared to draw arm, bow arm requires a huge force to resist the bow and force on draw arm during the archery activity. The bow arm is positioned forward straight hence the force being exert towards the shoulder joint. Archery activity involves six phases known as stance (S), nock arrow (NA), pre draw (PD), full draw (FD), release (R) and follow through (FT).
Archery can be classified into modern and traditional archery, depending on the construction of bow. In modern archery, recurve or compound bow equipped with technological advancement tools such as arrow rest, bow sight, pulley, stabilizer, launcher rest, mechanical release and clicker are used in order to shoot the aim accurately [3-6]. In the other hand, traditional archery is constructed by traditional bows and arrows with no modern tools [7]. Common traditional bows used are self-bow and composite bow [7, 8]. Self-bows are constructed using single wooden sticks whereas composite bows are built by a layer of materials for instances, laminated wood, horn, sinew that glued by a collagen-based adhesive [9]. Unlike modern, shooting accuracy in traditional archery could be obtained through practices and techniques. There are several techniques in traditional archery, for instance Khatrah technique. The technique involves grasp (stance), locking (nocking), drawing, releasing and sighting (follow through) [10]. This technique emphasises on the sighting part, whereby a bow remains straight with a target while the wrist is adducted and the hand is punched forward to rotate upper end bow. Therefore the muscles forces produced on bow arm is higher compared to the draw arm.

Modern archery has been performed in the most international competition such as commonwealth and Olympic due to its accuracy, ease of use and portability [2, 11-16]. In order to enhance the performance of the archer, many research works have been carried out [1, 3, 17-25]. Physiological measures refer to the combination of physiological signals such as electrocardiogram (ECG), electromyography (EMG) and electroencephalogram (EEG) [26]. However most of the research is carried out by measuring muscle activity using EMG sensor. The EMG is broadly used in detecting muscle electrical signal [27], in many field such as biomedical [28], sports sciences [13, 29, 30], rehabilitation [31] and commonly in ergonomics [32]. Study in [1] and [25] have reported that high performance of archer attained at less muscles activity in modern archery. 
Recently, traditional archery has been exposed to international competition due to its simple construction of bow while reserving its heritage culture. Different from modern, traditional archery requires more energy during draw phase in order to sustaining the pulling force of the bow string [33]. To indicate the applied energy, muscle forces of archers are gauged. High muscle force and rapid movement of muscle force could lead to muscle fatigue and further serious possible injuries $[34,35]$. More importantly, this could affect performance of the archer. Hence, research on finding suitable muscle force of archers in traditional archery has been performed. Yet, the scope of the research might varies and miscellaneous.

Therefore, in this study, muscle force of upper extremity in traditional archery using Khatrah technique is computed. Muscle data of upper extremity which are located at upper arm, lower arm and trunk body part are recorded using EMG and analyse for six phases of archery activity. The estimated muscle forces that generated then will be identified as a muscle fatigue and a possible risk of injuries. In addition, the result of this study can be used as a performance measurement for beginners who want to improve their next-level skills.

\section{PROPOSED METHODOLOGY}

The overall process of analysing upper extremity force of muscle in traditional archery is shown in Figure 1. The proposed method involves four stages; data acquisition, data filtering, normalization and smoothing and muscle force analysis. Firstly, data acquisition. In this stage, EMG sensors are placed on an archer's muscles at upper arm, lower arm and trunk body part. The data is recorded during six phases of archery cycle. Secondly, the data is filtered and normalised prior to the calculation of muscle force. Lastly, the muscle force analysis, whereby muscle force for bow and draw arm is computed for all phases are then compared. Each of the steps in the proposed method as shown in Figure 1 is elaborated in detail in this section.

\subsection{Data Acquisition}

This stage can be divided into two components; equipment used and procedure.

\subsubsection{Equipment}

In this study, EMG Works Analysis version 4.0.7 (DelSys-DE-2.1 Differential EMG sensors) is employed to record muscle data during archery activity. The instrument has electrode with two parallel silver bar dimensional $1 \mathrm{~cm}$ with $1 \mathrm{~cm}$ gap to each other. The experiment procedures is prepared according to SENIAM's recommendations and approved by UKM ethic committee (UKM PPI/111/8/JEP-2016-559). Meanwhile, for data analysis, R programming is implemented.

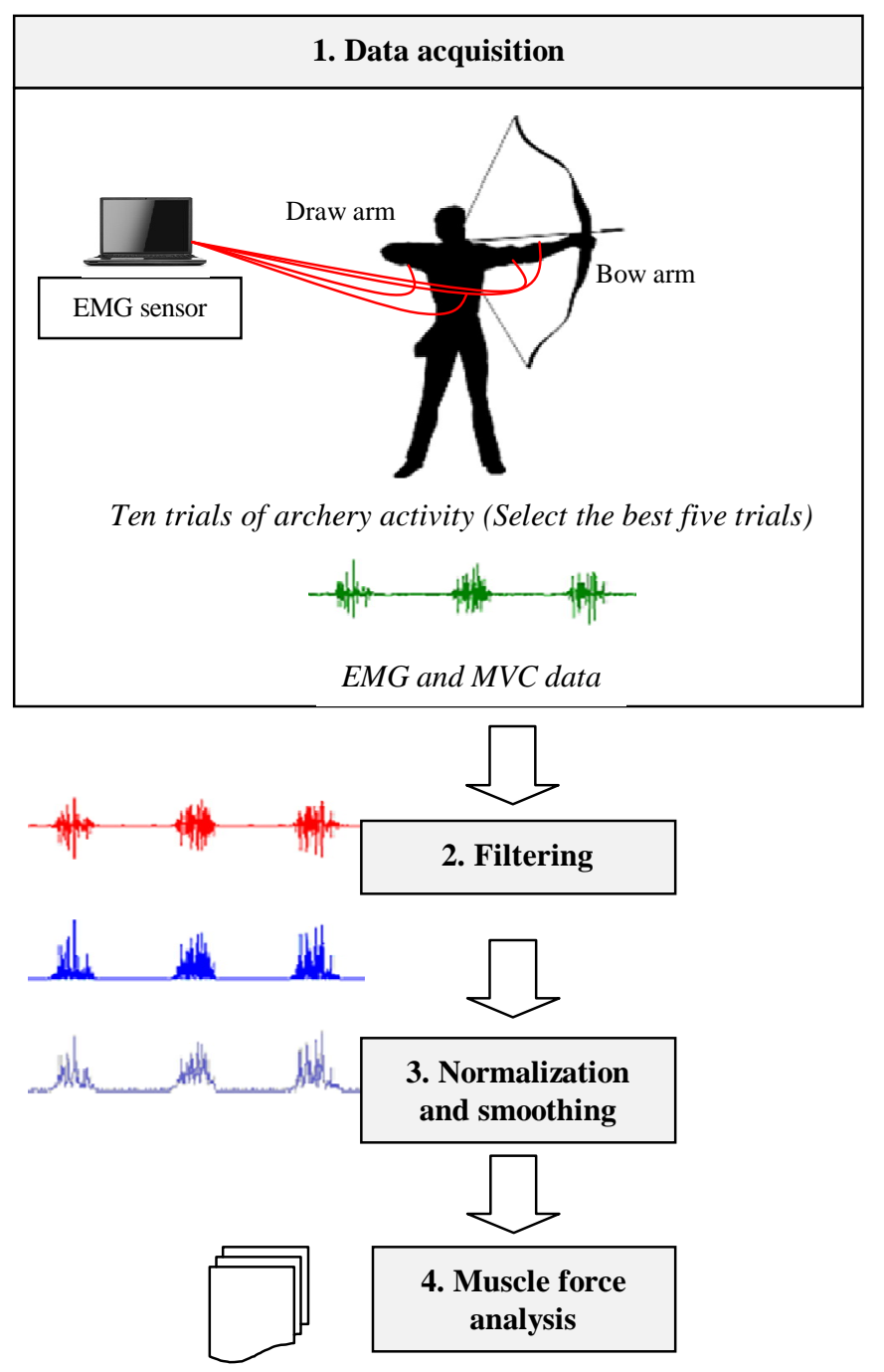

Figure 1: Process involved in the proposed methodology

\subsubsection{Procedure}

In this study, a champion of the World Horseback Archery Championship in Korea 2014 (who having weight and height of $75 \mathrm{~kg}$ and $170 \mathrm{~cm}$, respectively) is requested to perform archery activity using a traditional composite bow with $45 \mathrm{lb}$ for ten trials including resting between each trial. Then, only five best trials are selected. In order to avoid injury, the subject is required to perform muscles stretching prior to the activity.

Then, EMG sensors are placed on the subject's muscle. As mentioned earlier, archery is a static sport which focuses on upper extremity muscles of bow arm and draw arm. The upper extremity muscles can be categorized into three parts of body which are upper arm, lower arm and trunk. Muscles at the upper arm are medial deltoid (DELT), triceps brachii (TRI), biceps brachii (BIC) and brachioradialis (BRA). For lower arm, flexor carpi radialis (FCR), extensor carpi ulnaris (ECU) and extensor digitorum communis (EDU), while lattisimus 
dorsi (LAT), pectoralis mejor (PECT), and medial trapezius (TRAP) are for trunk part, as illustrated in t.

Hence, EMG sensors are placed on the ten muscles. EMG data and maximum voluntary contraction (MVC) are recorded for six temporal phases of draw and bow arm of archery cycle. The six phases are stance (S), nock arrow (NA), pre draw (PD), full draw (FD), release (R) and follow through (FT).

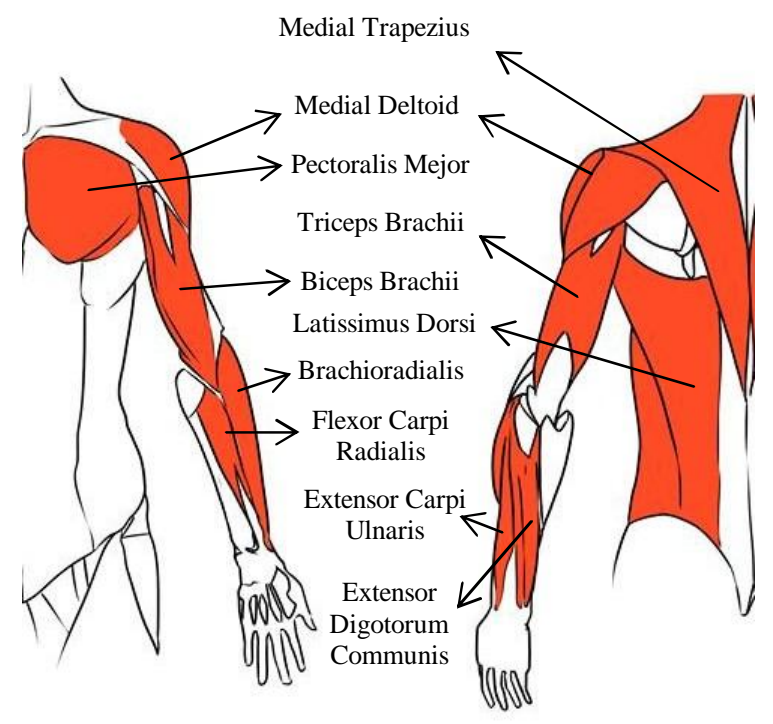

Figure 2: Muscles at the upper arm, lower arm and trunk

\subsection{Filtering}

Then, the EMG and MVC data are filtered through two stages, pre-filtering and post-filtering. The filtering process is done through the kit of EMG sensor. In the pre-filtering process, the recorded EMG and MVC data are full-wave rectified and filtered with Bagnoli-4 output band pass width, low pass width, sampling rate, maximum impedance and common mode rejection ratio (CMRR) are set from $20 \mathrm{~Hz}-450 \mathrm{~Hz}, 4$ $\mathrm{Hz}-450 \mathrm{~Hz}, 1000 \mathrm{~Hz}$, and 92dB respectively.

Then, in the post-filtering stage, the pre-filtered data are filtered using Butterworth band pass filter in order to attain absolute data. Lastly, in order to suppress the noise, the absolute data are filtered with a low pass filter.

\subsection{Normalisation and Smoothing}

In this stage, the filtered data are normalised in order to standardise data within a time frame. The filtered data with various time frame numbers are attained for the five trial of archery activities. Therefore, to synchronise the time frame of the data, data normalization is performed by dividing an EMG (X) and MVC data (Y) as in (1);

$$
Z_{i}=\frac{X_{1}, X_{2}, X_{3}, \ldots, X_{n}}{Y_{j}} ; i=1,2, \ldots, 10 ; j=1,2, \ldots, 10
$$

where,

$$
\begin{aligned}
& Z_{i}=\text { Normalized of EMG } / \text { Normalized of MVC } \\
& X=\text { EMG data at each time frame } \\
& Y_{j}=j^{\text {th }} \text { of MVC for each muscle. }
\end{aligned}
$$

However, the normalised data consists of sharp edges. Hence, smoothing technique called spline interpolation is used to smoothen the data for better presentation.

\subsection{Muscle Force Analysis}

Then, to calculate muscle force $\left(F_{k}\right)$ for each muscle, the normalised data, $\left(Z_{i}\right)$ are multiplied with the maximum values of force, $f_{\max j}$ as in (2):

$$
F_{k}=Z_{i} \times f_{\max j} ; \quad k=1,2,3, \ldots, 10 .
$$

Where, $f_{\max j}$ is a product between maximum muscle stress and physiological cross sectional area (pCSA) of each muscle.

In this study, the pCSA and muscle stress are attained from [36-38], as depicted in Table 1. The pCSA is chosen by considering properties of the subject such as weight and height which implies to the cadaver used in the literature and muscle stress is selected from flexion-extension group of muscles. All these values are used to estimate the muscle

\begin{tabular}{|c|c|c|c|c|}
\hline No. & Group & Muscles & $\begin{array}{l}p C S A \\
\left(\mathrm{~cm}^{2}\right)\end{array}$ & $\begin{array}{l}\text { Muscle Stress } \\
\left(\mathrm{Ncm}^{-2}\right)\end{array}$ \\
\hline 1 & \multirow{4}{*}{ Shoulder } & DELT & 8.2 & 100 \\
\hline 2 & & PECT & 3.7 & \multirow{3}{*}{62} \\
\hline 3 & & LAT & 2.8 & \\
\hline 4 & & TRAP & 3.61 & \\
\hline 5 & \multirow{3}{*}{ Elbow } & TRI & 5.7 & 62 \\
\hline 6 & & BIC & 4.5 & \multirow{2}{*}{100} \\
\hline 7 & & BRA & 1.9 & \\
\hline 8 & \multirow{3}{*}{$\begin{array}{c}\text { Lower Arm } \\
\text { and Hand }\end{array}$} & FCR & 1.6 & 100 \\
\hline 9 & & ECU & 2.1 & \multirow{2}{*}{62} \\
\hline 10 & & EDU & 0.8 & \\
\hline
\end{tabular}
forces. According to [36], the muscle stress is varies according to group of muscle, as shown in Table 1.

Table 1: Muscles pCSA and muscle stresses for muscles [36-38]

\section{RESULTS AND DISCUSSION}

In this section, results attained from ten muscles (medial deltoid (DELT), triceps brachii (TRI), biceps brachii (BIC), brachioradialis (BRA), flexor carpi radialis (FCR), extensor carpi ulnaris (ECU), extensor digitorum communis (EDU), lattisimus dorsi (LAT), pectoralis mejor (PECT) and medial trapezius (TRAP)) for six phases of archery; stance (S), nock arrow (NA), pre draw (PD), full draw (FD), release (R) and follow through (FT) at both draw and bow arm are elaborated and discussed. The muscle force is obtained from the average of five trials. 


\subsection{Results of Muscle Force on Draw Arm}

Results of muscle forces for six phases on draw arm is presented in Table 2. Obviously, a high muscle force for all six phases is attained for triceps brachii (TRI), which is located at the upper arm. This is followed by pectoralis mejor (PECT) muscle at the trunk body part. The highest muscle force is attained at the phase of $\mathrm{S}$ for TRI $(387 \mathrm{~N})$ and PECT $(236 \mathrm{~N})$. The high muscle force indicates that these two muscles are acted as major muscles to pull the bow string during the archery activity. Due to the high muscle force, triceps brachii (TRI) and pectoralis mejor (PECT) may be suffered from muscle fatigue which then will lead to a possible risk of injuries. For upper arm, brachioradialis (BRA) muscle shows a low force at the phase of $\mathrm{S}$ and a high force at the FT. For lower arm, it can be seen that the flexor carpi radialis (FCR) obtained a high muscle force $(136 \mathrm{~N})$ at the phase of FD. This is because the highest muscle forces produced by the hand are in a holding position (aiming target) before the string is released.

In other hand, a consistent force could be obtained for both extensor carpi ulnaris (ECU) and extensor digitorum communis (EDC) at the phase of NA onwards. Meanwhile, for trunk body part, a significant transition muscle forces can be seen for latissimus dorsi (LAT) and medial trapezius (TRAP) in the phase of S to R. This scenario will benefit the archer as this trunk body part of the muscles plays a role in supporting the force generated by the bow, since the size of the muscle appears to be larger than that of the other upper body part. This phenomenon helps the archer by preventing muscle tiredness in the upper and lower arms.Interestingly, it can be seen that for draw arm, muscle at upper arm and trunk requires more force as attained high average muscle force, compared to lower arm. Hence, in order to avoid muscle fatigue and any possible injuries risk, precautious must be taken by the archers at these two body parts at the particular phase.

Table 2: Muscle forces by phases for draw arm

\begin{tabular}{|c|c|c|c|c|c|c|c|}
\hline \multirow{2}{*}{ Cluster } & \multirow{2}{*}{ Muscles } & \multicolumn{7}{|c|}{ Force of Muscle (N) } \\
\cline { 2 - 8 } & & $(\mathrm{S})$ & $(\mathrm{NA})$ & $(\mathrm{PD})$ & $(\mathrm{FD})$ & $(\mathrm{R})$ & $(\mathrm{FT})$ \\
\hline \multirow{4}{*}{$\begin{array}{c}\text { Upper } \\
\text { arm }\end{array}$} & DELT & 85 & 98 & 105 & 102 & 111 & 164 \\
\cline { 2 - 8 } & TRI & $\mathbf{3 8 7}$ & $\mathbf{3 7 0}$ & $\mathbf{3 6 7}$ & $\mathbf{3 6 0}$ & $\mathbf{3 5 9}$ & $\mathbf{3 5 7}$ \\
\cline { 2 - 8 } & BIC & 54 & 65 & 63 & 59 & 48 & 20 \\
\cline { 2 - 8 } & BRA & 7 & 12 & 47 & 124 & 155 & 164 \\
\cline { 2 - 8 } & Mean & $\mathbf{1 3 3 . 3}$ & $\mathbf{1 3 6 . 3}$ & $\mathbf{1 4 5 . 5}$ & $\mathbf{1 6 1 . 3}$ & $\mathbf{1 6 8 . 3}$ & $\mathbf{1 7 6 . 3}$ \\
\hline \multirow{4}{*}{$\begin{array}{c}\text { Lower } \\
\text { arm }\end{array}$} & FCR & 19 & 47 & 88 & $\mathbf{1 3 6}$ & 132 & 82 \\
\cline { 2 - 8 } & ECU & 38 & 52 & 43 & 48 & 60 & 60 \\
\cline { 2 - 8 } & EDC & 3 & 24 & 14 & 20 & 21 & 22 \\
\cline { 2 - 8 } & Mean & $\mathbf{2 0}$ & $\mathbf{4 1}$ & $\mathbf{4 8 . 3}$ & $\mathbf{6 8}$ & $\mathbf{7 1}$ & $\mathbf{5 4 . 7}$ \\
\hline \multirow{4}{*}{ Trunk } & PECT & $\mathbf{2 3 6}$ & $\mathbf{2 2 5}$ & $\mathbf{2 1 3}$ & $\mathbf{2 0 5}$ & $\mathbf{2 0 0}$ & $\mathbf{1 8 9}$ \\
\cline { 2 - 8 } & LAT & 10 & 10 & 93 & 159 & 170 & 146 \\
\cline { 2 - 8 } & TRAP & 74 & 81 & 68 & 136 & 164 & 119 \\
\cline { 2 - 8 } & Mean & $\mathbf{1 0 6 . 7}$ & $\mathbf{1 0 5 . 3}$ & $\mathbf{1 2 4 . 7}$ & $\mathbf{1 6 6 . 7}$ & $\mathbf{1 7 8}$ & $\mathbf{1 5 1 . 3}$ \\
\hline
\end{tabular}

\subsection{Results of Muscle Force on Bow Arm}

Table 3 shows the force of muscle for six phases at bow arm. At the phase of $\mathrm{S}$ and NA, the first two higher force is obtained at the upper arm; biceps brachii (BIC) and brachioradialis (BRA).

Furthermore, it can be observed that the force of medial deltoid (DELT) is increased significantly and then decreased at the phase of FT. The drastic transition from the phase of NA $(132 \mathrm{~N})$ to PD $(527 \mathrm{~N})$ shows that the burden exert to the shoulder has occurred. Therefore support from other muscle is needed at this stage in order to avoid the risk of muscle fatigue and injury. This could be done by adjusting on the muscle coordinate by an appropriate archery technique. Interestingly, the force of brachioradialis is plummeted for all phases. It indicates that the muscle has a low risk of tiredness and injury.

For muscle force of lower arm, similar pattern of force can be observed for both flexor carpi radialis (FCR) and extensor digitorum communis (EDC) whereby the force increases through the first five phases and eventually decreased at the phase of FT. High muscle force at the phase of R $(176 \mathrm{~N})$ indicates that flexor carpi radialis (FCR) is highly affected when the archer applied Khatrah technique.

Meanwhile, the pattern of force for trunk body part is similar for all muscles. The muscle force is increased at the phase of NA and then it is decreased at the phase of R onwards. This similar pattern could minimise the risk of muscle fatigue as the work load is equally distributed to each muscle.

Table 3: Muscle forces by phases for bow arm

\begin{tabular}{|c|c|c|c|c|c|c|c|}
\hline \multirow{2}{*}{ Cluster } & \multirow{2}{*}{ Muscles } & \multicolumn{7}{|c|}{ Force of Muscle (N) } \\
\cline { 2 - 8 } & & $(\mathrm{S})$ & $(\mathrm{NA})$ & $(\mathrm{PD})$ & $(\mathrm{FD})$ & $(\mathrm{R})$ & $(\mathrm{FT})$ \\
\hline \multirow{4}{*}{$\begin{array}{c}\text { Upper } \\
\text { arm }\end{array}$} & DELT & 31 & 132 & $\mathbf{5 2 7}$ & $\mathbf{7 5 9}$ & $\mathbf{8 0 0}$ & $\mathbf{7 3 4}$ \\
\cline { 2 - 8 } & TRI & 37 & 43 & 133 & 226 & 258 & 282 \\
\cline { 2 - 8 } & BIC & $\mathbf{1 8 8}$ & $\mathbf{1 8 9}$ & 87 & 91 & 127 & 160 \\
\cline { 2 - 8 } & BRA & 153 & 153 & 145 & 140 & 152 & 187 \\
\cline { 2 - 8 } & Mean & $\mathbf{1 0 2 . 3}$ & $\mathbf{1 2 9 . 3}$ & $\mathbf{2 2 3}$ & $\mathbf{3 0 4}$ & $\mathbf{3 3 4 . 3}$ & $\mathbf{3 4 0 . 8}$ \\
\hline \multirow{4}{*}{$\begin{array}{c}\text { Lower } \\
\text { arm }\end{array}$} & FCR & 29 & 75 & 91 & 159 & 176 & 133 \\
\cline { 2 - 8 } & ECU & 19 & 42 & 7 & 44 & 88 & 112 \\
\cline { 2 - 8 } & EDC & 5 & 13 & 27 & 46 & 50 & 41 \\
\cline { 2 - 8 } & Mean & $\mathbf{1 7 . 7}$ & $\mathbf{4 3 . 3}$ & $\mathbf{4 1 . 7}$ & $\mathbf{8 3}$ & $\mathbf{1 0 4 . 7}$ & $\mathbf{9 5 . 3}$ \\
\hline \multirow{4}{*}{ Trunk } & PECT & 55 & 84 & 124 & 171 & 152 & 79 \\
\cline { 2 - 8 } & LAT & 17 & 53 & 111 & 118 & 100 & 45 \\
\cline { 2 - 8 } & TRAP & 33 & 75 & 170 & 218 & 194 & 106 \\
\cline { 2 - 8 } & Mean & $\mathbf{3 5}$ & $\mathbf{7 0 . 7}$ & $\mathbf{1 3 5}$ & $\mathbf{1 6 9}$ & $\mathbf{1 4 8 . 7}$ & $\mathbf{7 6 . 7}$ \\
\hline
\end{tabular}




\subsection{Comparison of Average Muscle Force between Draw Arm and Bow Arm}

By comparing the average muscle force of upper arm and lower arm at draw arm and bow arm, it can be seen that the average muscle force on bow arm is higher than the draw arm. It is proven that the bow arm requires more force due to supporting forces that produced by the draw arm as well as to holding the strength of the bow due to resistant of the bow arm during the shooting. Meanwhile, high muscle force at trunk body can be seen for draw arm. Hence, in order to reduce the muscle fatigue, archers may focus on possible techniques that require less muscle force for bow arm. Therefore, this could enhance shooting performance as well as to minimise the possible injury risk.

Furthermore, it is proven that the most affected muscle is flexor carpi radialis (FCR), using Khatrah technique. It can be seen that high muscle force $(176 \mathrm{~N})$ is obtained for FCR at the $\mathrm{R}$ phase of bow arm. As mentioned earlier, the Khatrah technique emphasizes the thumb and index finger, which is theoretically linked to these fingers by the FCR muscle.

\section{CONCLUSIONS AND RECOMMENDATIONS}

This study presents upper extremity muscle force for traditional archery using Khatrah technique. In order to avoid muscle fatigue, which then lead to possible injury risk, muscle force is gauged in six phases of traditional archery for draw arm and bow arm. The results shows that high muscle force is obtained at bow arm; specifically muscles at upper and lower arm at different phase of archery. This is because the muscle forces produced by drawing the arm is held by the bow arm since the straight forward position of the bow arm is exerted towards the archer's shoulder joint. In addition, it can be seen that for draw arm, high muscle force is obtained at the trunk body. Therefore, by knowing the muscle force in the archery phases, muscle exhaustion and risk of injury could be prevented, as well as the shooting performance of the archer could be tracked and enhanced. Furthermore, the forces generated by the world class archer could be used as a benchmark of muscle fatigue or risk of injury for other level of archer. For future work, a comparison of muscle force between professional and beginner level archers will be carried out.

\section{EDITORIAL POLICY}

The authors declare that there is no conflict of interest in this publication.

\section{ACKNOWLEDGEMENT}

The author thanked Ministry of Higher Education, Malaysia (MOHE) for the scholarship awarded under MyBrain, MyPhD.

\section{REFERENCES}

[1] Erkek, M.E. and C. Tinazci. Shooting Dynamics in Archery. in 6th World Congress of Biomechanics (WCB 2010). August 1-6, 2010 Singapore. 2010. Springer.

[2] Ahmad, Z., et al. Biomechanics measurements in archery. in International Conference on Mechanical Engineering Research (ICMER2013). 2013.

[3] Zanevskyy, I., Compound archery bow asymmetry in the vertical plane. International Sports Engineering Association, 15(10): pp. 167-175. 2012.

[4] Rieckmann, M., J. Codrington, and B. Cazzolato. Modelling the vibrational behaviour of composite archery arrows. in Proceedings of the Australian Acoustical Society conference. 2011.

[5] Martin, E. and A.-M. Bebak. Aerospace Analysis for a Non-Aerospace Archery Application. in 51st AIAA Aerospace Sciences Meeting including the New Horizons Forum and Aerospace Exposition. 2013.

[6] Stone, R.T. The biomechanical and physiological link between archery techniques and performance. in Proceedings of the human factors and ergonomics society annual meeting. 2007. SAGE Publications Sage CA: Los Angeles, CA.

[7] Kooi, B.W. and C.A. Bergman, An approach to the study of ancient archery using mathematical modelling. Antiquity, 71(271): pp. 124-134. 1997.

[8] Grayson, C.E., M. French, and M.J. O'Brien, Traditional Archery from Six Continents: The Charles E. Grayson Collection. University of Missouri Press. 2007.

[9] Gunduz, G., et al., Anatomy of Wooden Core of Ottoman Composite Archery Bows. Sains Malaysiana, 42(5): pp. 547-552. 2013.

[10] Latham, J. and W. Paterson, Saracen archery: An English version and exposition of a Mameluke work on archery (ca. AD 1368), 1970, The Holland Press: London.

[11] Mann, D.L. and N. Littke, Shoulder injuries in archery. Canadian Journal of Sports Sciences, 14(2): pp. 85-92. 1989.

[12] Fukuda, H. and C.S. Neer, Archer's shoulder : Recurrent posterior subluxation and dislocation of the shoulder in two archers. Journal of Orthopedics, 11(1): pp. 171-174. 1988.

[13] Clarys, J., et al., Muscular activity of different shooting distances, different release techniques, and different performance levels, with and without stabilizers, in target archery. Journal of Sports Sciences, 8(3): pp. 235-257. 1990. 
[14] Rayan, G.M., Archery-related injuries of the hand, forearm, and elbow. Journal of Southern Medical Journal, 85(10): pp. 961-964. 1992.

[15] Kooi, B.W., Bow-arrow interaction in archery. Journal of Sports Sciences, 16(1): pp. 721-731. 1998.

[16] Delahaye, H., et al., The Shoulder of The Archer: Clinical, Video and Isokinetic Evaluation. Journal of Isokinetics and Exercise Science, 13(1): pp. 81-86. 2005.

[17] Ariffin, M.S. and A.S. Rambely. Optimization of Upper Extremity Muscles Using Compound Bow via Lagrange Multiplier Method (LMM). in Advances in Industrial and Applied Mathematics. 2016. Pulai Spring Resort, Johor Bahru: AIP Conference Proceedings.

[18] Ariffin, M.S. and A.S. Rambely. Comparison of upper limb muscles behaviour for skilled and recreational archers using compound bow. in AIP Conference Proceedings. 2017. AIP Publishing.

[19] Ariffin, M.S., A.S. Rambely, and N.M. Ariff, Wrist muscle activity of khatrah approach in Mameluke technique using traditional bow archery. AIP Conference Proceedings, 1940(1): pp. 020121. 2018. https://doi.org/10.1063/1.5028036

[20] Kian, A., F.T. Ghomshe, and Z. Norang, Comparing the ability of controlling the bow hand during aiming phase between two elite and beginner female compound archers: A case study. European Journal of Experimental Biology, 3(4): pp. 103-111. 2013.

[21] Pekalski, R., Experimental and theoretical research in archery. Journal of Sports Sciences, 8(3): pp. 259-279. 1990.

[22] Ertan, H., et al., Activation patterns in forearm muscles during archery shooting. Journal of Human Movement Science, 22(1): pp. 37-45. 2003.

[23] Pagitz, M. and K.-U. Bletzinger, Shape optimization of a bow. Structural and Multidisciplinary Optimization, 28(1): pp. 73-76. 2004.

[24] Horsak, B. and M. Heller, A three-dimensional analysis of finger and bow string movements during the release in archery. $J$ Appl Biomech, 27(2): pp. 151-160. 2011.

[25] Tinazci, C. Shooting dynamics in archery: A multidimensional analysis from drawing to releasing in male archers. in 5th Asia-Pacific Congress on Sports Technology: Impact of Technology on Sport IV, APCST. 2011. Melbourne, VIC.

[26] Jennalyn N. Mindoro, C.D.C., Alvin Sarraga Alon, Mon Arjay F. Malbog, Julie Ann B. Susa, Drowsy or Not?Early Drowsiness Detection utilizing Arduino Based on Electroencephalogram (EEG) Neuro-Signal. International Journal of Advanced Trends in Computer Science and Engineering, 9(2): pp. 2221-2226. 2020.

https://doi.org/10.30534/ijatcse/2020/200922020

[27] Basmajian, J.V. and C.J. De Luca, Muscles alive: their functions revealed by electromyography. Williams \& Wilkins. 1985.
[28] Weddell, G., B. Feinstein, and R. Pattle, The clinical application of electromyography. The Lancet, 241(6234): pp. 236-239. 1943.

[29] Martin, P.E., W.L. Siler, and D. Hoffman, Electromyographic analysis of bow string release in highly skilled archers. Journal of Sports Sciences, 8(3): pp. 215-221. 1990.

[30] Clarys, J.P., Electromyography in sports and occupational settings: an update of its limits and possibilities. Ergonomics, 43(10): pp. 1750-1762. 2000.

[31] Guttmann, L. and N.C. Mehra, Experimental studies on the value of archery in paraplegia. Journal of International Spinal Cord Society, 11(2): pp. 159-165. 1973.

[32] V. Padmanathan, I.H., and T. Y. Wei, Application of pressure biofeedback unit as part of ergonomics assessment tools for assessing back pain among computer users. International Journal of Advanced Trends in Computer Science and Engineering, 8(3): pp. 879-882. 2019. https://doi.org/10.30534/ijatcse/2019/83832019

[33] Zolkafi, M.A.A., et al. Effects of eight weeks traditional archery training on heart rate variability among sedentary youth. in AIP Conference Proceedings. 2019. AIP Publishing LLC.

[34] McLean, S.G. and J.E. Samorezov, Fatigue-induced ACL injury risk stems from a degradation in central control. Medicine and science in sports and exercise, 41(8): pp. 1661-1672. 2009.

[35] Woods, C., et al., The Football Association Medical Research Programme: an audit of injuries in professional football: an analysis of ankle sprains. British Journal of Sports Medicine, 37(3): pp. 233-238. 2003.

[36] Buchanan, T.S. and D.A. Shreeve, An Evaluation of Optimization Techniques for the Prediction of Muscle Activation Patterns During Isometric Tasks. Journal of Biomechanical Engineering, 118(4): pp. 565-574. 1996.

[37] Garner, B.A. and M.G. Pandy, Musculoskeletal model of the upper limb based on the visible human male dataset. Comput Methods Biomech Biomed Engin, 4(2): pp. 93-126. 2001.

[38] Holzbaur, K.R., W.M. Murray, and S.L. Delp, A model of the upper extremity for simulating musculoskeletal surgery and analyzing neuromuscular control. Annals of biomedical engineering, 33(6): pp. 829-840. 2005. 